\title{
Dental Stem Cell Therapy with Calcium Hydroxide in Dental Pulp Capping
}

\author{
Young-Min Ji, D.D.S., M.S., ${ }^{1,2, *}$ Soung Hoo Jeon, Ph.D., ${ }^{1,2, *}$ \\ Joo-Young Park, D.D.S., ${ }^{1,2}$ Jong-Hoon Chung, Ph.D., ${ }^{3}$ \\ Yun-Hoon Choung, D.D.S., M.D., Ph.D., ${ }^{4}$ and Pill-Hoon Choung, D.D.S., Ph.D. ${ }^{1,2}$
}

Calcium hydroxide has been extensively and steadily used for direct pulp capping in modern clinical dentistry. As it was known to have potential to induce hard tissue repair, this chemical has been applied to the exposed dental pulp and the hard tissue is expected to be regenerated above the pulp. During the reparative process of exposed pulp, primary odontoblasts that were lost as a result of extensive damage are replaced with newly differentiated odontoblast-like cells. This process is known to follow the sequential steps of proliferation, migration, and differentiation of progenitor cells. This research will examine the relationship between calcium hydroxide and the recruitment, proliferation, and mineralization of postnatal dental stem cells, obtained from an immature dental tissue of beagle dogs. Immunocytochemical staining and reverse transcriptase-polymerase chain reaction were used to identify the putative stem cell markers. Immunoblot analysis, wound healing assay, cell migration assay, and alizarin red staining were used to evaluate proliferation, migration, and mineralization capacity of the calcium hydroxide-treated stem cells. As an in vivo study, a combination of calcium hydroxide and autologous dental pulp stem cells (DPSCs) was applied for the treatment of intentionally created tooth defects on the premolars and the molars in beagle dogs to observe dentin regeneration. Ex vivo expanded DPSCs and periodontal ligament stem cells expressed STRO-1 and CD146, the mesenchymal stem cell markers. It was evident that calcium hydroxide increased recruitment, migration, proliferation, and mineralization of the DPSCs and periodontal ligament stem cells. Such results are valuable for future availability of DPSCs, which are recently focused as the stem cell reservoir for regeneration of dentin upon tooth injury, as well as for elucidation of the role of calcium hydroxide in pulp capping therapy.

\section{Introduction}

D ENTAL PULP is often exposed during clinical processes such as tooth preparation and removal of dentinal decay accidentally or inevitably. In certain cases, the direct pulp capping has been used as a solution to maintain pulp health and function. Studies on the capping materials have been carried out by many clinicians and researchers, as the selection of the capping material is the key to produce a good treatment outcome. The ideal functions that a direct pulp capping material should display are infection controlling ability, adhesiveness to dentin to prevent microleakage, ease in handling, and promotion of dentin bridge formation. ${ }^{1}$ For the past 60 years, dentists have been using calcium hydroxide as a direct pulp capping material on vital pulp exposure to induce reparative dentin formation. It was also used as a cavity liner, which was applied above the dentin to accelerate reactive dentin formation indirectly. The evidence of calcium hydroxide accelerating dentin formation is known to lie in its biological properties. When calcium hydroxide contacts the exposed vital pulp, the high alkaline $\mathrm{pH}$ of the preparation induces a burn of limited amplitude at the surface of the pulp exposure. ${ }^{2}$ When a certain period of time elapses after the formation of the scar, the majority of the inflammatory cells disappear, and the cells that relate to dentin regeneration appear at the site. However, it remains unclear which specific cells participate in the regeneration stage.

The study on the dentin regenerative effects of bioactive molecules had begun long after introduction of calcium

\footnotetext{
${ }^{1}$ Department of Oral and Maxillofacial Surgery, Dental Research Institute and ${ }^{2}$ Tooth Bioengineering National Research Laboratory, BK21, School of Dentistry, Seoul National University, Seoul, Korea.

${ }^{3}$ Department of Biosystems and Biomaterials Science and Engineering, College of Agriculture and Life Science, Seoul National University, Seoul, Korea.

${ }^{4}$ Department of Otolaryngology, School of Medicine, Ajou University, Suwon, Korea.

*These two authors contributed equally to this work.
} 
hydroxide as a treatment drug in dentistry. Rutherford et al. reported that indirect pulp capping using bone morphogenetic protein-7 (BMP-7) accelerated the formation of reactive dentin, and the direct pulp capping experiment in monkey also showed that BMPs aided in the regeneration of dentin., Goldberg et al. reported the result of using bone sialoprotein and BMP-7 for pulp capping of the artificially created deficient area on the upper molar of rat and it was by far more effective in dentin regeneration compared with the control group. ${ }^{5}$ As such, many recent experiments have aimed at examining the regenerative properties of dentin using bioactive molecules in pulp capping, but the influence of direct cell implantation therapy on dentin regeneration has not been elucidated. The identification of putative dental stem cell populations capable of regenerating organized tooth-like structures has increased interest in the potential use of postnatal stem cell-based therapies for dental tissue regeneration following trauma or disease. ${ }^{6-10}$

The dental pulp is a highly vascularized tissue and some of the conservative procedures in clinical dentistry, such as direct pulp capping and pulpotomy procedures, result in blood vessel injury. The injured endothelial cells release chemotactic factors, which signal the molecules to initiate the inflammatory process, and also express the adhesion molecules that are necessary in recruiting the inflammatory and progenitor cells for the initiation of the healing process. ${ }^{11,12}$ It was suggested that the injury of the endothelial cell participates in the recruitment of odontoblast-like cells to the injury site. ${ }^{13}$ This raises the issue of the application of stem cells and signal molecules into the treatment modalities of conservative pulp therapies and traumatic teeth treatment.

In this study, we investigated the possibility of pulp capping therapy with dental stem cell in tooth injury and the role of calcium hydroxide in pulp capping. The regeneration of dentin via autologous stem cell graft and the elucidation of the mechanism of calcium hydroxide in pulp capping therapy were tried for the first time in this research, although the hard tissue repair through some signaling molecules or scaffold has been introduced in other studies.

This research will examine the relationship between calcium hydroxide and the recruitment, proliferation, and mineralization of two types of dental stem cells, dental pulp stem cells (DPSCs) and periodontal ligament stem cells (PDLSCs) obtained from immature teeth of beagle dogs. As an in vivo study, a combination of calcium hydroxide and autologous DPSCs was applied for the treatment of intentionally created tooth defects on the premolars and the molars in three beagle dogs to observe dentin regeneration. Based on such results, the mechanism of calcium hydroxide, which has been selected as first choice of drug for dentin regeneration, has to be proved and a new method has to be presented for the clinical usage of cell therapy with dental stem cells.

\section{Materials and Methods}

\section{Primary cells}

All procedures were carried out according to the guidelines for the Animal Care Committee of Seoul National University, School of Dentistry. After extracting molar teeth from three 1-year-old beagle dogs, the pulp tissue and periodontal ligament were carefully separated. The isolated tissue was digested in a solution of $3 \mathrm{mg} / \mathrm{mL}$ collagenase type I
(Worthington Biochem, Freehold, NJ) and $4 \mathrm{mg} / \mathrm{mL}$ dispase (Boehringer, Mannheim, Germany) for $1 \mathrm{~h}$ at $37^{\circ} \mathrm{C}$. Cell suspensions were cultured in the $\alpha$-modification of Eagle's medium (Gibco BRL, Grand Island, NY) supplemented with $10 \%$ fetal bovine serum (Equitech-Bio, Kerrville, TX), $100 \mu \mathrm{M}$ ascorbic acid 2-phosphate (Wako, Tokyo, Japan), $2 \mu \mathrm{M}$ glutamine, $100 \mathrm{U} / \mathrm{mL}$ penicillin, and $100 \mu \mathrm{g} / \mathrm{mL}$ streptomycin (Biofluids, Rockville, MD). Cell suspensions were incubated at $37^{\circ} \mathrm{C}$ in $5 \% \mathrm{CO}_{2}$. All primary cells were used in their second or third passage. Percentage of STRO-1-positive cells was analyzed by flow cytometry, as STRO-1 was known as a putative mesenchymal stem cell marker. Cells were harvested in phosphate-buffered saline (PBS) containing $2 \mathrm{mM}$ ethylenediaminetetraacetic acid, washed once with PBS, fixed in 3.7\% paraformaldehyde, and incubated with antiSTRO-1 antibody 1:100 (volume/volume) dilution in PBS for $60 \mathrm{~min}$ at $4^{\circ} \mathrm{C}$ in the dark, then incubated with second antimouse antibody 1:500 (volume/volume) dilution in PBS for $30 \mathrm{~min}$ at $4^{\circ} \mathrm{C}$ in the dark, and finally analyzed with a FACS Vantage cell sorter (Becton-Dickinson, Mountain View, CA). The data were analyzed using a Mod-Fit 2.0 cell cycle analysis program (Becton-Dickinson).

\section{Immunocytochemical and histological examination}

To identify the putative postnatal stem cells from the cultured cells, the expression of STRO-1, a cell surface marker for mesenchymal stem cells, was confirmed by immunocytochemistry. Isolated stem cells from the dental pulp and periodontal ligament were seeded at $1 \times 10^{4}$ cells/well in sixwell plates on $22 \times 22 \mathrm{~mm}$ cover slips and cultured for $24 \mathrm{~h}$ at $37^{\circ} \mathrm{C}$ in $5 \% \mathrm{CO}_{2}$. After being washed in PBS ( $\mathrm{pH} \mathrm{7.4)} \mathrm{and}$ $3.7 \%$ paraformaldehyde in $\mathrm{PBS}$ at $\mathrm{pH} 7.4$, the cells were permeabilized for $15 \mathrm{~min}$ on ice with $0.1 \%$ Triton $\mathrm{X}-100$ in PBS and blocked with $1 \%$ bovine serum albumin overnight at $4{ }^{\circ} \mathrm{C}$. Then the cells were incubated with STRO- 1 antibody (1:200; R\&D Systems, Minneapolis, MN) for $2 \mathrm{~h}$. The cells were subsequently incubated with anti-mouse IgG-Cy3 (Zymed Laboratories, Carlsbad, CA) for $1 \mathrm{~h}$. Then the nuclei were stained with $4^{\prime}$,6-diamidino-2-phenylindole (DAPI) $(2 \mu \mathrm{g} / \mathrm{mL})$ for $30 \mathrm{~min}$. Four to 6 weeks after direct pulp capping, the premolars were carefully extracted. After fixation in buffered formalin solution for $96 \mathrm{~h}$, the specimens were decalcified in 12\% ethylenediaminetetraacetic acid for 4 weeks at room temperature. Four-micrometer-thick serial bucco-lingual sections were cut longitudinally through the center of the exposure site. Sections were then processed for hematoxylin and eosin staining. Immunohistochemical staining was performed on premolar specimens obtained from the beagle dog. Briefly, paraffin sections $(4 \mu \mathrm{m})$ were dewaxed and hydrated with alcohol series. After antigen retrieval in citrate buffer, the sections were treated with hydrogen peroxide. The sections were then incubated with the anti-STRO-1, anti-dentin bone sialoprotein antibodies, and DAPI. Cells and tissues were imaged using a LSM 510 META confocal laser scanning (Carl Zeiss, Göttingen, Germany).

\section{Reverse transcriptase-polymerase chain reaction}

Total RNA was prepared using Trizol reagent (Invitrogen, Carlsbad, CA) according to the manufacturer's protocol. The first-strand cDNA was synthesized using a first-strand cDNA synthesis kit (Invitrogen). The primer set for poly- 
merase chain reaction (PCR) included CD146 (sense, $5^{\prime}$-TAC CCC ATT CCT CAA GTC-3'; antisense, 5'-TCA GAC ACA TAG TTC ACC AG-3') and glyceraldehyde-3-phosphate dehydrogenase (sense, $5^{\prime}$-TCT CAA CTA CAT GGT GTA CA- $3^{\prime}$; antisense, $5^{\prime}$-GGA AAT GAG CTT GAC AAA GT-3'). The PCRs were preincubated in a PCR Mastercycler gradient (Eppendorf, Hamburg, Germany) at $95^{\circ} \mathrm{C}$ for $3 \mathrm{~min}$ and then cycled 33 times at $95^{\circ} \mathrm{C} / 30 \mathrm{~s}, 55^{\circ} \mathrm{C} / 45 \mathrm{~s}$, and $72^{\circ} \mathrm{C} / 60 \mathrm{~s}$, followed by a final $10 \mathrm{~min}$ extension at $72^{\circ} \mathrm{C}$. The products were separated by electrophoresis on a $1 \%$ agarose gel and visualized by ultraviolet-induced fluorescence.

\section{Selection of the most reactive stem cells to calcium hydroxide}

After exposing the cultured stem cells to various concentrations of calcium hydroxide, the stem cell colony was cultured to observe the dose-dependent effects of calcium hydroxide. Considering that the effective dose of calcium hydroxide is different for the tissue and cells, four types of concentrations of calcium hydroxide were each diluted by 10 -folds, along with a control group containing no calcium hydroxide. Through this result, the stem cell with the best reactivity with calcium hydroxide can be selected, and the optimal condition can be discovered.

\section{Western blot analysis}

To evaluate the proliferative capability of the calcium hydroxide-treated stem cells, western blot analysis was performed as resolved on $10 \%$ sodium dodecyl sulfatepolyacrylamide gel electrophoresis. ${ }^{14}$ Anti-phosphor extracellular signal-regulated protein kinase (p-ERK; Santa Cruz Biotechnology, Santa Cruz, CA) and anti-ERK (Santa Cruz Biotechnology) primary antibodies were used and then incubation with horseradish peroxidase-conjugated secondary antibodies (Santa Cruz Biotechnology) was carried out. Protein bands were observed by enhanced chemiluminescence (Amersham Biosciences, Piscataway, NJ).

\section{BrdU incorporation}

For BrdU incorporation, DPSCs or PDLSCs were seeded onto $22 \times 22 \mathrm{~mm}$ cover slips in six-well plates at $2 \times 10^{4}$ cells per well. BrdU (Roche Applied Science, Indianapolis, IN) was added at a final concentration of $20 \mu \mathrm{M}$ and the cells were further incubated for $8 \mathrm{~h}$ at $37^{\circ} \mathrm{C}$. Cells were washed twice with PBS and then fixed in 3.7\% paraformaldehyde at $4^{\circ} \mathrm{C}$ for $10 \mathrm{~min}$. Cells were permeabilized with $0.1 \%$ Triton $\mathrm{X}$ 100 at $4^{\circ} \mathrm{C}$ for $5 \mathrm{~min}$ and then gently washed three times with PBS. Cells were incubated with mouse anti-BrdU monoclonal antibody (Dako, Carpinteria, CA) at a 1:100 dilution for $2 \mathrm{~h}$ at room temperature, incubated with goat anti-mouse-CyTM2conjugated secondary antibody at a 1:1000 dilution for $30 \mathrm{~min}$ at room temperature, and then washed five times with PBS. BrdU was incorporated into proliferating cells only, so that cellular proliferation was assessed. For nuclear staining, DAPI dihydrochloride (Roche Applied Science) was used at a final concentration of $1 \mu \mathrm{g} / \mathrm{mL}$ in PBS for $5 \mathrm{~min}$, followed by extensive washing with PBS. Cover slips were mounted and then the cells were viewed using a confocal imaging system. Each analysis was performed at least three times.

\section{Wound healing assay and cell migration assay}

The influence of calcium hydroxide on the recruitment and migration of the stem cells can be observed by carrying out a wound healing assay on the selected stem cells, under an optimal condition. To produce an in vitro wound healing, DPSCs and PDLSCs were grown to confluence and mechanically scratched to remove a fixed area of cells. Cell migration was measured by the in vitro scratch wound healing assay. Monolayer cells were scratched with a sterile pipette tip in six-well plastic dishes. The migratory ability of the cells was evaluated by measuring the number of cells within the scratched wound at $0,6,12$, and $24 \mathrm{~h}$.

The influence of calcium hydroxide on the recruitment and migration of stem cells can be observed by carrying out a cell migration assay on the selected stem cells, under an optimal condition. The control group consisted of cells grown in a culture containing no calcium hydroxide, and the experimental group consisted of cells grown in a culture containing $1 \mu \mathrm{g} / \mathrm{mL}$ of calcium hydroxide as final concentration. Approximately $5 \times 10^{3}$ cells were seeded, and the migration rate was calculated and compared by comparing the number of cells before swab and after swab, showing the number of cells that passed the insert and adhered to the lower surface of the membrane, of each of the control and experimental group.

\section{Mineralization induction}

The influence of calcium hydroxide on the mineralization of the stem cell can be observed by carrying out alizarin red staining on the selected stem cells, under an optimal condition. DPSCs and PDLSCs were used for the experiment, each comparing the control group containing no calcium hydroxide and the experimental group containing calcium hydroxide. Also, $8 \times 10^{4}$ cells were seeded in six-well dishes, each of the groups was cultured in a normal growth media and a mineralization induction media, supplemented with $5 \mathrm{mM} \beta$-glycerophosphate and $10 \mathrm{nM}$ dexamethasone (Sigma, St. Louis, MO), and then the results were compared. The experimental procedure was as follows: first, the fixation stage consisted of removing the growth media, then PBS washing, and then finally adding $2 \mathrm{~mL}$ of ice-cold $70 \%$ ethanol and settling in room temperature for $10 \mathrm{~min}$. An appropriate amount of $40 \mathrm{mM}$ alizarin red $(\mathrm{pH} 4.2)$ solution was then added to the dish and left in the shaking incubator at $50 \mathrm{rpm}$ at room temperature for $30 \mathrm{~min}$. A photograph was taken after three repetitions of PBS washing and then drying. The alizarin red-stained sample was added with $3 \mathrm{~mL}$ of $10 \mathrm{mM}$ sodium phosphate- $10 \%$ acetylpyrimidium ( $\mathrm{pH} 7.0)$ solution, followed by the destaining procedure and incubating at room temperature for $15 \mathrm{~min}$. The destained sample was then transferred to a 96-well plate and the absorbance was measured at $562 \mathrm{~nm}$.

\section{Stem cell autograft in beagle dog dental defect model}

Three beagle dogs (aged 1 year) were used for this investigation. These animals were anesthetized with an intravenous injection of Zolazepam $(0.3 \mathrm{~mL} / \mathrm{kg}$, Zoletil50; Virbac, Carros cedex, France) with $2 \%$ Rompun $(0.15 \mathrm{cc} / \mathrm{kg}$, Xylazine HCL; Bayer, Leverkusen, Germany). We prepared an access to the mesial aspect of the premolars in the cervical part of the 
coronal pulp, but not in the pulp horn. We also used electrosurgery to remove the papillary gingiva before any cavity preparation. This allowed a more consistent preparation of the half-moon cavities in the cervical area of the beagle dog premolars. Then we drilled half-moon class $\mathrm{V}$ cavities in 1-2 s at the cervical third with a no. 331 inverted cone carbide bur. This cervical location allows a better mechanical resistance to occlusal pressures, and consequently, fewer restorative fillings with glass ionomer (GI) cements are lost. The residual dentin is then pushed with a steel probe, which allows obtaining a pulp exposure of a limited size. This process avoids stretching of the pulp tissue around the bur and uncontrolled pulp damages. ${ }^{15}$ The cavities were rinsed with physiological serum and gently dried with a cotton pellet before being capped. Prepared cavities as such were divided into four groups for the experiment. The defective area of group 1, the control group, was set to apply no stem cells or calcium hydroxide but with only GI, group 2 with selected DPSCs and GI, group 3 with calcium hydroxide and GI, and group 4 with calcium hydroxide-treated DPSCs and GI. Each group has two times repeats to the two premolars in one animal, totaling 24 premolars in all four quadrants in three animals.

\section{Statistical analysis}

Data are expressed as the mean \pm standard deviation. Statistical significance of differences between groups was analyzed by Student's $t$-test. A $p$-value of less than 0.05 was considered statistically significant $(p \leq 0.05)$.

\section{Results}

\section{Isolation and characterization of DPSCs and PDLSCs}

We isolated putative postnatal dental stem cells from dental pulp and periodontal ligament. Most of the cells retained their fibroblastic spindle shape ${ }^{6}$ (Fig. 1B). To identify the putative postnatal stem cells from the cultured cells, the expression of STRO-1 was confirmed by immunocytochemistry. The isolated cell populations expressed the cell surface molecule STRO-1, a mesenchymal stem cell marker ${ }^{6}$ (Fig. 1B). The expression of STRO-1 is evident in both the DPSCs and PDLSCs, revealing a tendency to distribute mainly on the surface of the cell. As a control, ACHN cells, a renal carcinoma cell line, did not express STRO-1. Also, as the result of operating the reverse transcriptase-PCR through a selfdesigned primer of CD146, known as a mesenchymal stem cell marker, a uniform-sized band was evident in both DPSCs and PDLSCs ${ }^{16}$ (Fig. 1A). Using the flow cytometry cell sorting, we obtained a STRO-1 cell population. The results confirmed that the STRO-1-positive cells were expressed at $31 \%$ on DPSCs and at $27 \%$ on PDLSCs.

\section{Proliferation of DPSCs and PDLSCs at different calcium hydroxide concentrations}

To identify the route of ERK activation by calcium hydroxide, we measured the activities of the p-ERK after calcium hydroxide treatment on the proliferation of DPSCs and PDLSCs by western blotting. The concentrations of calcium hydroxide were $0,0.1,1.0$, and $10.0 \mu \mathrm{g} / \mathrm{mL}$ as final concentrations. The final concentration of $1 \mu \mathrm{g} / \mathrm{mL}$ was made by adding $1 \mu \mathrm{L}$ of $10 \mathrm{mg} / \mathrm{mL}$ calcium hydroxide stock into the $100 \mathrm{~mm}$ culture dish with $10 \mathrm{~mL}$ of media.
As a result, in the case of the cells grown in the culture with a low concentration of calcium hydroxide, the activation level of p-ERK was significantly increased compared with the control. The PDLSCs grown in the culture with high concentration of $1 \mathrm{mg} / \mathrm{mL}$ calcium hydroxide showed a low activation level in p-ERK and the level of total protein ERK did not change as a loading control (Fig. 2). The ERK pathway is a major transforming pathway and is the main signaling pathway of the mediated cell in this article. ERK1/2 are important members of the enzyme family mitogenactivated protein kinases. ERK $1 / 2$ acts as the hinge of mitogen-activated protein kinase access. Activation of ERK1/2 results in phosphorylation of transcription factors that induces the regulation of genes, increasing cell proliferation and protecting cells against apoptosis (Fig. 2A). ${ }^{17,18}$

Proliferating cell nuclear antigen was originally identified as an antigen that is expressed in the cell nuclei during DNA synthesis phase of cell cycle. It was also known as angiographic and improves morphological vasospasm significantly. ${ }^{19}$ We have also exposed cells to different concentrations of calcium hydroxide for evaluation of cell toxicity and available working dosage for cell proliferation in vitro system. These results indicate proliferation of the cells, especially through the elevation of $\mathrm{p}$-ERK and proliferating cell nuclear antigen protein levels (Fig. 2A). We also measured the accurate $\mathrm{pH}$ in the medium after treatment of calcium hydroxide at the $10 \mu \mathrm{g} / \mathrm{mL}$ concentration. The level of $\mathrm{pH}$ was mildly increased from $\mathrm{pH} 7.4$ to 7.56 .

To determine whether calcium hydroxide activated cellular proliferation, we measured the percentage of BrdU incorporation stimulated by calcium hydroxide in DPSCs and PDLSCs. The relative numbers of BrdU-positive cells were increased from $25 \%$ to $49 \%$ (Fig. $2 \mathrm{~B}$ ).

\section{Calcium hydroxide activates cell motility}

A wound healing assay was used to assess the migration of cultured DPSCs and PDLSCs at the fixed time points. The migratory aspect of the cell was measured by counting the number of cells observed in between the fixed primary widths of the wound edge, at a certain site for each time point. In the cases of DPSCs and PDLSCs, the migration of the cells significantly increased from $12 \mathrm{~h}$ approximately in the group with $10 \mu \mathrm{g} / \mathrm{mL}$ of calcium hydroxide compared with the control group (Fig. 3A). To evaluate the migration of the cells in a different way, cell migration assay was operated. The cell migration assay compares cell migration by counting the number of cells before and after swabbing on the insert membrane. DPSCs in the control group showed that $30 \%$ of the cells seeded passed the insert membrane and remained adhered even after swabbing the upper surface (without calcium hydroxide); however, the DPSCs in the group with calcium hydroxide showed a greater percentage $(60 \%)$ of cell migration at $24 \mathrm{~h}$. PDLSCs, similarly, showed that $32 \%$ of the cells passed the insert in the control group, whereas $58 \%$ of the cells migrated in the group treated with calcium hydroxide (Fig. 3B).

\section{Calcium hydroxide activates mineralization}

The effect of calcium hydroxide-induced mineralization was confirmed by the alizarin red staining (Fig. 4, right panel). Mineralization of both the DPSCs and PDLSCs was 


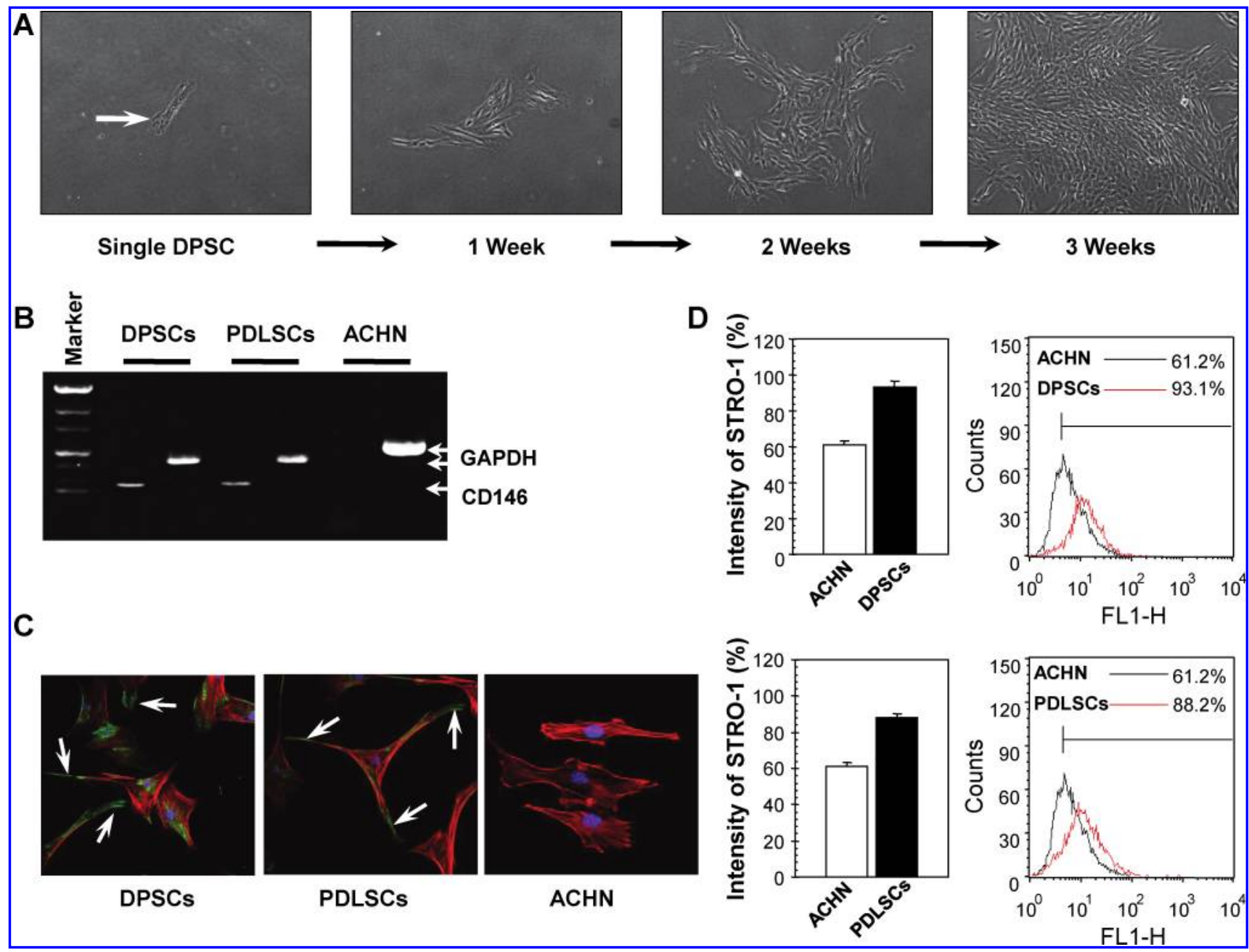

FIG. 1. Characterization of dental pulp stem cells (DPSCs) and periodontal ligament stem cells (PDLSCs). (A) Lightmicroscopic view of the adherent single-cell colony of DPSCs (arrows). (B) Reverse transcriptase-polymerase chain reaction (RT-PCR) analysis of DPSCs and PDLSCs. Polymerase chain reaction (PCR) shows the presence of $510 \mathrm{bp}$ in CD146 and $800 \mathrm{bp}$ in GAPDH. ACHN shows the negative control of STRO-1. (C) Immunocytochemical staining using STRO-1, as a mesenchymal stem cell marker. Cells were incubated with anti-STRO-1 antibody, followed by labeling with anti-mouse fluorescein isothiocyanate for STRO-1 (arrows). Cytoskeleton was visualized in red by labeling phalloidin with confocal microscope. 4',6-Diamidino-2-phenylindole (DAPI)-stained nuclei are shown in blue. ACHN shows the negative control of mensenchymal stem cells (original magnification, $\times 630$ ). (D) Cytometric analyses for STRO-1 on DPSCs, PDLSCs, and ACHN cells. In the histograms, STRO-1 expression in DPSCs and PDLSCs showing an evident positivity; the black line indicates ACHN cells. GAPDH, glyceraldehyde 3-phosphate dehydrogenase. Color images available online at www .liebertonline.com/ten.

compared without calcium hydroxide (control: with PBS) or with calcium hydroxide (experimental) under normal growth or mineralization induction condition. The alizarin red-stained samples underwent destaining procedure, incubating the samples at room temperature for $15 \mathrm{~min}$ with $3 \mathrm{~mL}$ of $10 \mathrm{mM}$ sodium phosphate-10\% acetylpyrimidium ( $\mathrm{pH} 7.0)$ solution. The destained samples were then transferred to a 96-well plate and the absorbance was measured at $565 \mathrm{~nm}$ (Fig. 4, left panel). The mineralization results after 3 weeks showed that the DPSCs and PDLSCs cultured at $1 \mu \mathrm{g} / \mathrm{mL}$ calcium hydroxide concentration under the mineralization induction media have far higher mineralization reaction than under the normal growth media. However, the cells treated with PBS (control) and cultured under normal growth media did not show mineralization (Fig. 4, right panel). Also, when comparing the DPSCs and PDLSCs, the mineralization effect of DPSCs was greater (Fig. 4).

\section{Confirmation of calcification in the defected tooth}

To determine whether the calcified tissue is regenerated in the defect region, we analyzed the renascent region and calcified region in the group 1 (no graft but only GI), group 2 (DPSCs only), group 3 (calcium hydroxide and GI), and group 4 (DPSCs treated with calcium hydroxide), respectively (Fig. 5A, B). STRO-1 was stained by immunohistochemistry as a mensenchymal stem cell marker. Dentin sialoprotein was stained as a marker for dental regeneration. Manifestation of STRO-1 was the most clearly observed in group 4 (calcium hydroxide-treated DPSCs with GI) in all three animals (Fig. 5D). Such findings indicate that in the 


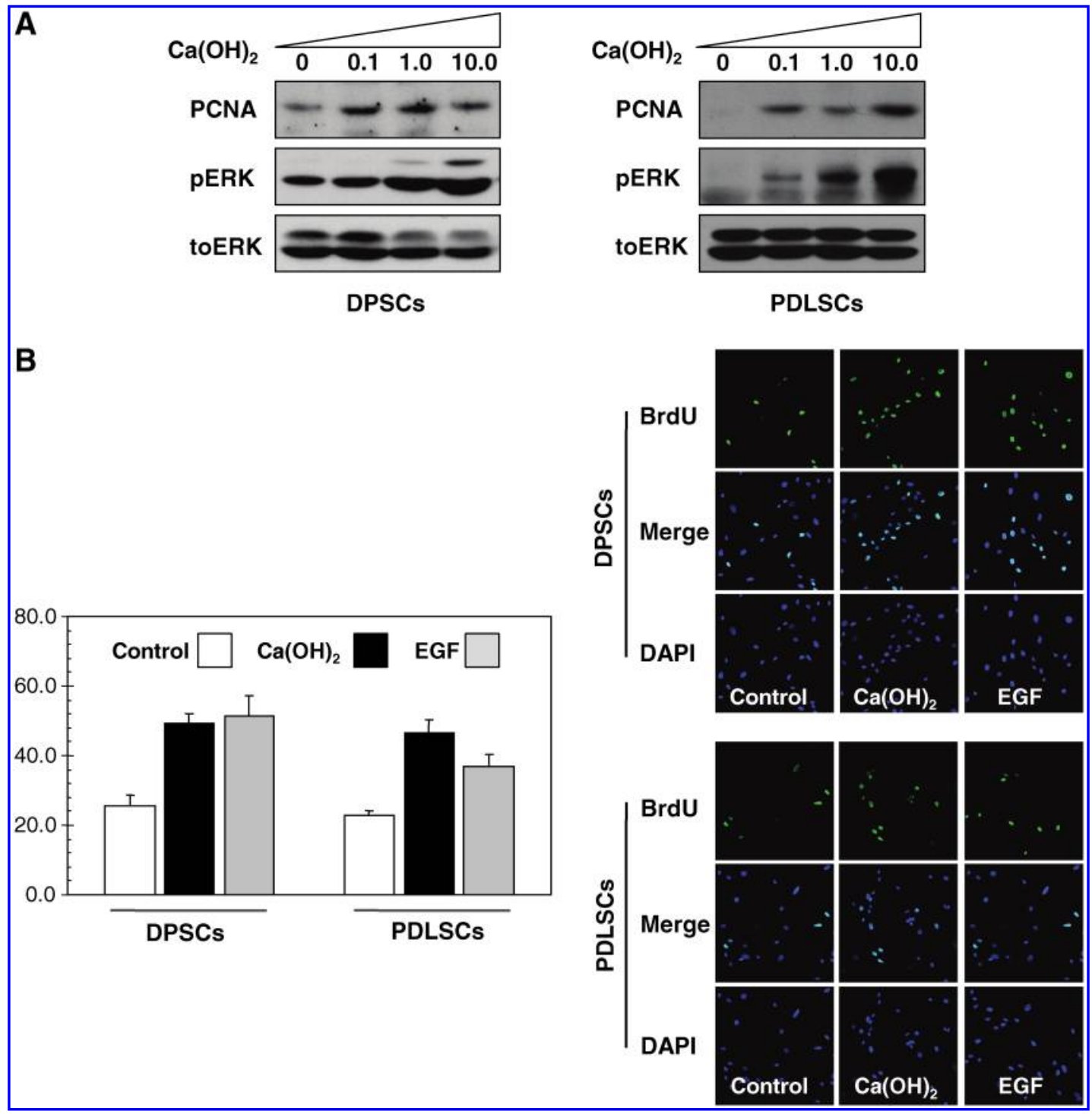

FIG. 2. The effects of calcium hydroxide on the proliferating activity of canine DPSCs and PDLSCs. (A) DPSCs and PDLSCs were grown in $\alpha$-modification of Eagle's medium with or without calcium hydroxide for the indicated dosage, supplemented with $10 \%$ heat-inactivated fetal bovine serum, ascorbic acid (final $100 \mu \mathrm{M})$, streptomycin $(100 \mu \mathrm{g} / \mathrm{mL}$ ), and penicillin $\mathrm{G}$ sodium $(100 \mu \mathrm{g} / \mathrm{mL})$ in $5 \% \mathrm{CO}_{2}$ at $37^{\circ} \mathrm{C}$. Cell extracts were resolved on $10 \%$ sodium dodecyl sulfate-polyacrylamide gel electrophoresis, and phosphor extracellular signal-regulated protein kinases (p-ERKs), ERKs, and proliferating cell nuclear antigen (PCNA) proteins were detected by western blot analysis as described in Materials and Methods section. (B) DPSCs and PDLSCs were either untreated or treated with $10 \mu \mathrm{g} / \mathrm{mL}$ calcium hydroxide for cell proliferating activity. BrdU was added at a final concentration of $20 \mu \mathrm{M}$ for $8 \mathrm{~h}$ to assess cellular proliferation. The cells were fixed, permeabilized, and incubated with anti-BrdU monoclonal antibody, followed by incubation with goat anti-mouse-CyTM2-conjugated secondary antibody. EGF was treated with final concentration of $10 \mu \mathrm{g} / \mathrm{mL}$ to the DPSCs and PDLSCs for the positive control of BrdU incorporated cells. Cell nuclei were stained with DAPI. Cells were visualized by a confocal microscope as described in Materials and Methods section. Cells exhibiting BrdU incorporation in the nucleus were scored as BrdU-positive cells. Error bars indicate the standard deviations of three independent analyses. Color images available online at www.liebertonline.com/ten.

regenerated region in group 4, the DPSCs have existed and been differentiated and calcified into dentin-like tissue. Hard tissue formation was rarely found in the group 1 pulp cavity but some inflammatory cells were infiltrated above the defected dentin layer. In group 3 (calcium hydroxide with GI), the necrotic tissue debris existed above the original dentin layer with inflammatory cell mixture. As for the necrotic layer formation in group 3 (calcium hydroxide with GI), several review articles reported that the connective tissue in direct contact with calcium hydroxide gives rise to a zone of necrosis, altering the physicochemical state of intercellular substance, which determines protein denaturation. In addition, antimicrobial action of calcium hydroxide due to its high $\mathrm{pH}$ in vivo was reported. The existence of massive granulation in the superficial granulosis zone and the zone of necrosis above the dentin layer, when calcium hydroxide contacted directly to the dentin, prohibit the release of calcium ion and delay dentin regeneration for some periods. For this reason, necrotic layer with mixture of inflammatory cells were only found in group 3, whereas in group 4 where 

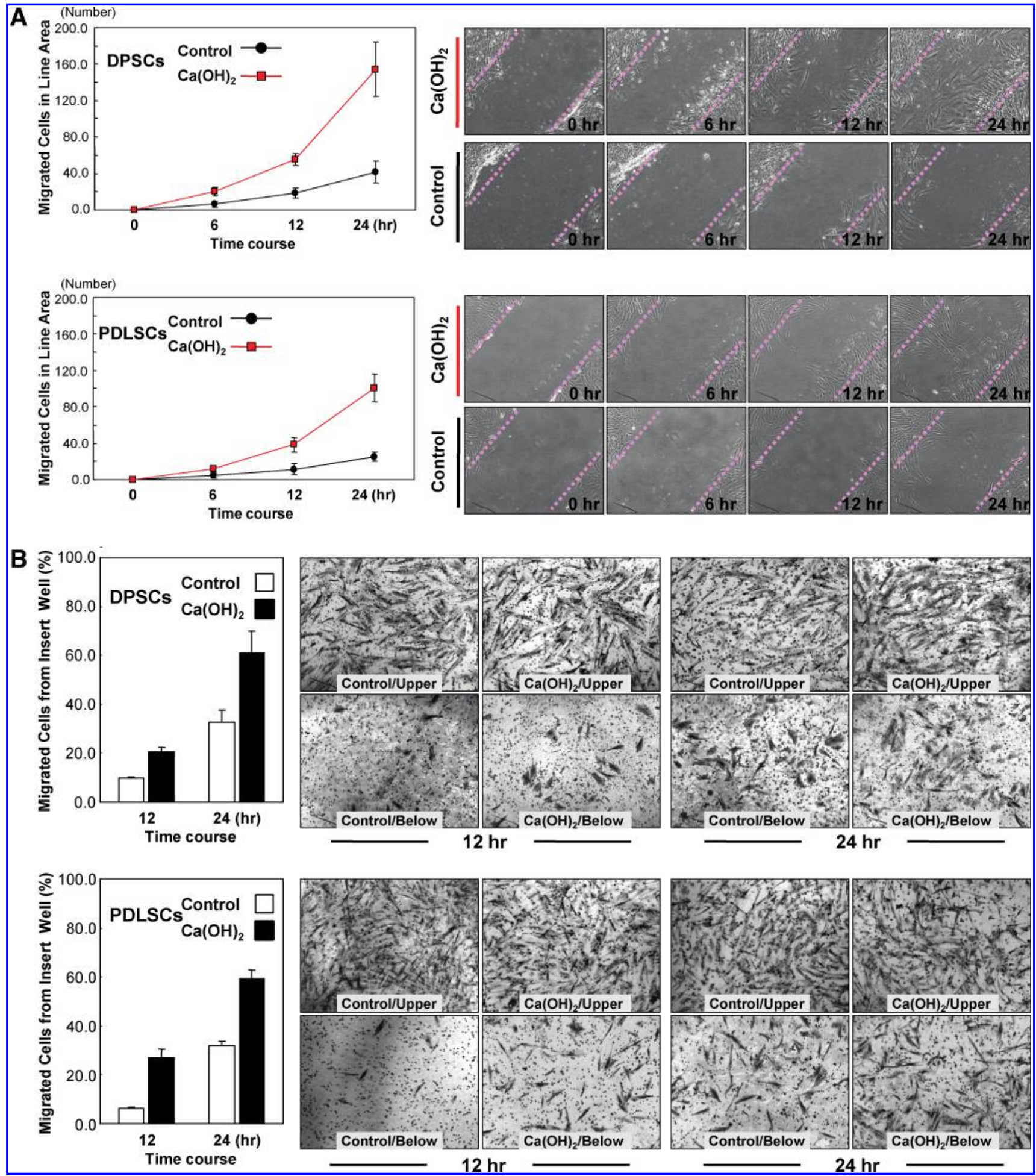

FIG. 3. Increase of the migration of DPSCs by calcium hydroxide in vitro. (A) Wound healing assay. Treatment of calcium hydroxide increased for DPSCs and PDLSCs to fill the wounded area. The graph represents the quantitative results for the number of cells migrating to the defined unit area. Analyses were performed at least three times. Representative data for the results are shown in the right panels. (B) Transwell migration assay. The average number of cells penetrating the filters increased for DPSCs and PDLSCs treated with calcium hydroxide. Color images available online at www.liebertonline .com/ten. 


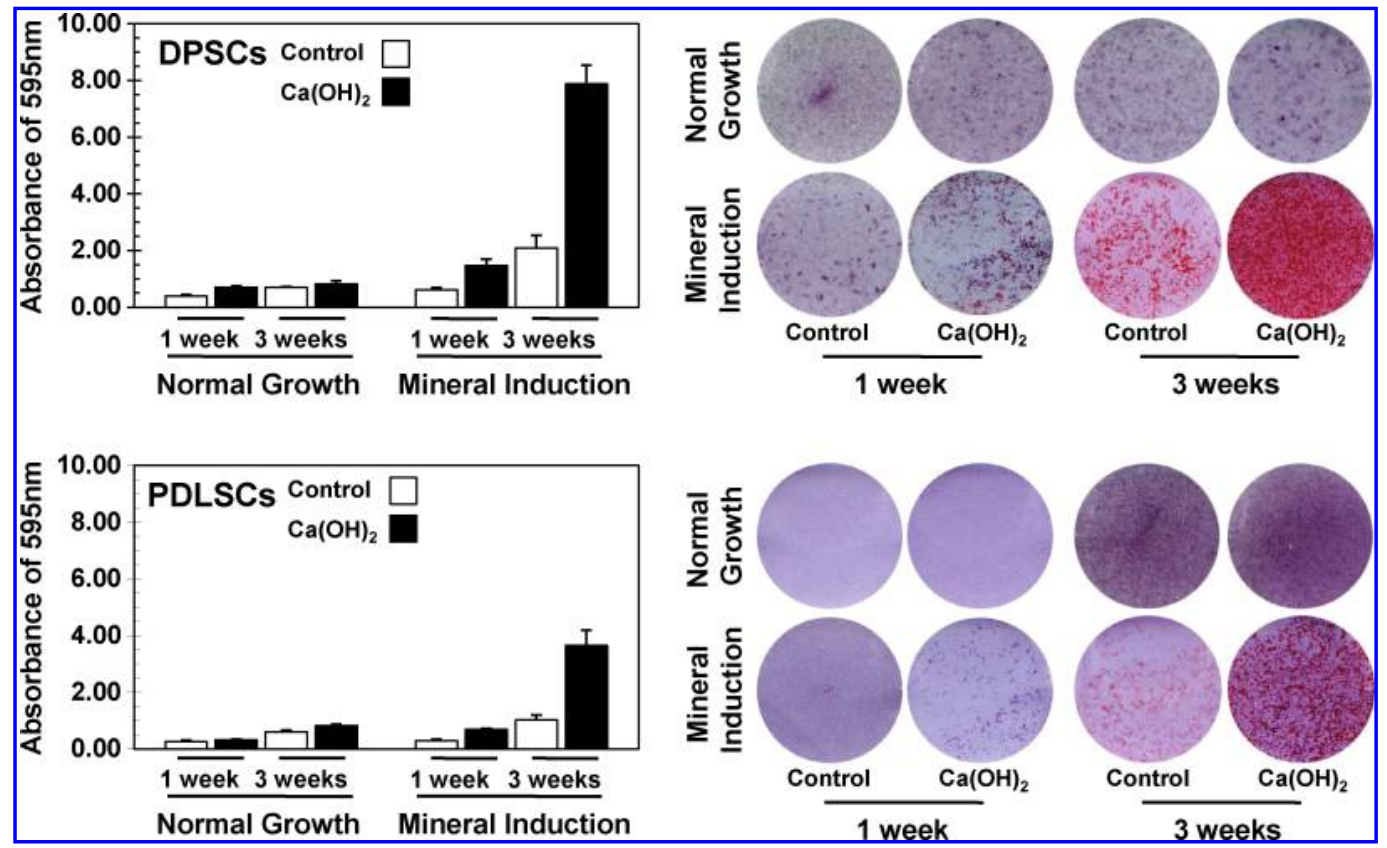

FIG. 4. Effects of mineralization on the calcium hydroxide of DPSCs and PDLSCs. DPSCs and PDLSCs were grown in $\alpha$ modification of Eagle's medium, and mineralization was induced with $\beta$-glycerophosphate and dexamethasone. Alizalin red staining showed mineral nodule formation with induction as described in Materials and Methods section. Note the significant mineralized nodules in the calcium hydroxide with induction media. Representative data for the results are shown in the right panels. Color images available online at www.liebertonline.com/ten.

the appropriate concentration of calcium hydroxide-treated DPSCs were grafted showed extensive dentin-like tissue formation in our experiment. These results proved that pulp capping with calcium hydroxide-treated DPSCs can be used in clinical application. ${ }^{20,21}$

\section{Discussion}

From the embryonic inner cell mass, pluripotent stem cells are isolated. However, most of the tissues of an adult organism generally include a small pool of cells (adult stem cells) with an inherent ability to maintain the pool through self-replication and produce more dedicated progenitor cells through multiple lineage differentiation. ${ }^{22}$ Postnatal stem cells have been found in various tissues, including bone marrow, neural tissue, skin, retina and, more recently, dental epithelium. ${ }^{23-25}$ These cells are usually inert within the normal adult tissue, but become active upon tissue injury to participate in the tissue repair process. $^{26}$ After primary dentinogenesis, the postmitotic odontoblasts, which secrete the primary dentin, remain functional and also secrete physiological secondary dentin continuously, but at a reduced rate. These cells retain the ability to respond to mild environmental stimuli and focally upregulate their secretory activity during reactionary dentinogenesis leading to dentinal regeneration. ${ }^{27}$ However, a stimulus of greater intensity may lead to the death of these odontoblasts. In such a case, a newly differentiated odontoblast-like cell from a precursor, during reparative dentinogenesis, will take over the role of dentinal regeneration. ${ }^{28}$

Although some observations during the regeneration of the dentin-pulp complex may explain the derivation of the stem/progenitor cells during reparative dentinogenesis, it remains indefinable. Potential derivations suggested that these stem/progenitor cells include a cell-rich layer of Höhl adjacent to the odontoblasts, perivascular cells, undifferentiated mesenchymal cells, and fibroblasts. ${ }^{29}$ Recently, Gronthos et al. had made the attempt to isolate postnatal human DPSCs. According to Gronthos et al., the DPSCs are capable of regenerating a dentin-pulp-like complex. Based on the result of the in vivo transplantation, the DPSCs were capable of forming ectopic dentin and associated pulp tissue, representing the adult stem cells, which possess high proliferative, self-renewal potentials and multilineage differentiation. $^{30}$

According to previous reports, the human bone marrow and the dental pulp tissue include postnatal stem cells that carry the ability to differentiate into osteoblast/odontoblasts, adipocytes, and neuron-like cells. Such stem cells were STRO-1/CD146-positive progenitors derived from the perivascular area of the bone marrow and dental pulp tissue. ${ }^{6,30,31}$ The process of local angiogenesis is commonly evident at all wound-healing sites, including that of the pulp. Hence, besides the obvious importance of nutrition supply during the healing process, the local angiogenesis may also increase the opportunity for the perivascular stem/ progenitor cell recruitment upon regeneration. The angiogenic growth factor sequestration and release in the dentin matrix are likely to be a key to the local upregulation of the angiogenesis during healing. ${ }^{32}$ It can be thought to have an indirect effect on the available pool of stem/progenitor cells necessary upon wound healing. In this study, we found that the DPSCs and PDLSCs from the beagle dogs are similar to the human mesenchymal stem cells with respect to their expression of STRO-1/CD146, implying that DPSCs and PDLSCs of the dog may also be derived from a pool of 

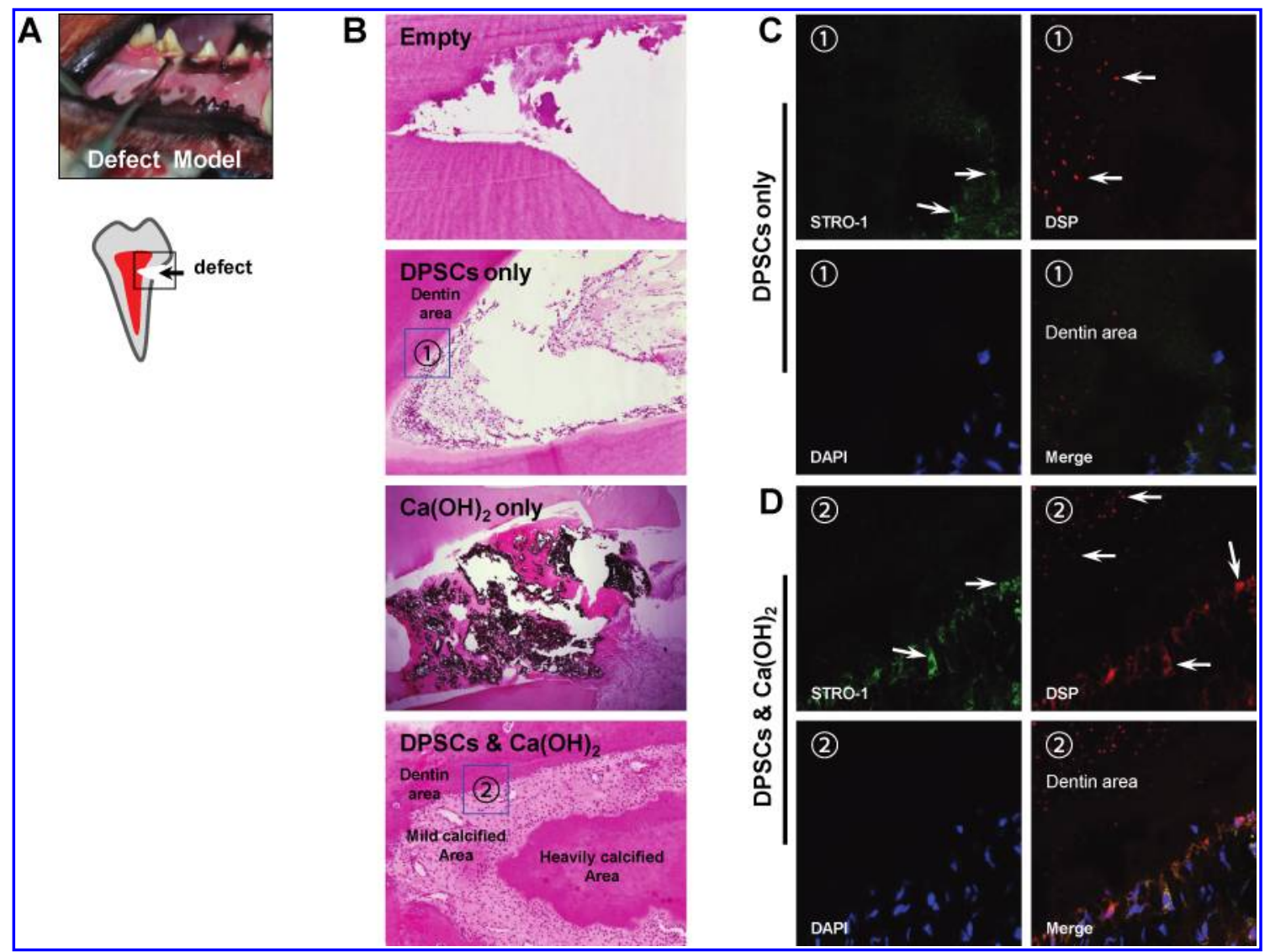

FIG. 5. Histological aspect of pulp capping area. (A) Schematic representation of the defect model and clinical photography of premolars in beagle dogs. (B) Hematoxylin and eosin-stained sections of defect area from premolar of beagle dogs. Hard tissue formation was rarely found in DPSCs only and $\mathrm{Ca}(\mathrm{OH})_{2}$ only teeth, whereas heavily calcified area was found in DPSCs treated with $\mathrm{Ca}(\mathrm{OH})_{2} .(\mathbf{C}, \mathbf{D})$ Boxed regions with circled letters in the regenerated area in contact with defect area are shown at high magnification. Immunohistochemical analysis was performed with antibodies against dentin sialoprotein (DSP) and STRO-1 in the group 2 (DPSCs only) or in the group 4 (DPSCs treated with calcium hydroxide). Arrows indicating green fluorescence are STRO-1 positive areas and red fluorescence are DSP positive areas. DAPI-stained nuclei are shown in blue. Note the abundance of calcification in the regenerated area in group 4 .

perivascular cells. The full sequence of dog-specific CD146 had not yet been registered in the gene bank, and therefore, in this study, we compared the currently known CD146 sequence of the human and mice. The common portions of the two sequences were used to carry out the reverse transcriptase-PCR after primer designing, and the final result shows a reproducible positive reaction in both DPSCs and PDLSCs as shown in Figure 1A. The dog-specific CD146 primer designed used for this study is thought to become of great use in the future as the mesenchymal stem cell marker of the dog.

To find out the effect of calcium hydroxide on the proliferation of DPSCs and PDLSCs, cultured cells from cultures of various concentrations of calcium hydroxide were used for observing the expression levels of p-ERK through western blotting. As a result, it was evident that in the case of cells grown in the culture with a low concentration of calcium hydroxide, the expression level of p-ERK was higher than the control in both DPSCs and PDLSCs. This implies that the low-concentration calcium hydroxide has positive effects on stem cell proliferation. The migration of the stem/progenitor cells to the injury site for differentiation into the newly dif- ferentiated odontoblast-like cells will be a key factor for cell recruitment during regeneration, but the vitality of the primary odontoblast is compromised. The evidence for the occurrence of such a migratory event is provided in a vast number of studies reporting that reparative dentinogenesis and dentin bridge formation occur in the pulp capping procedure. ${ }^{2,33-36}$ This aspect of regeneration remains an attractive area for further study, both in respect of maximizing the recruitment of progenitor cells, and also, through influencing the nature of the recruited cell population. If the necessary chemotactic signals for specific cell populations can be determined, this could be harnessed for directed recruitment of those cells to provide greater specificity to tissue response.

As such, the cell recruitment and migration play an important role in dentin regeneration process. Therefore, wound healing assay and cell migration assay were performed to find out whether calcium hydroxide, the most commonly used pulp capping agent until now, had effects on cell recruitment and migration. In the case of DPSCs, the number of cell migration was significantly increased in the groups with calcium hydroxide when compared with 
the control group, without calcium hydroxide, in both the wound healing assay and cell migration assay, as shown in Figure 3. Such a physiologic result matches the biochemical aspect of the previous experiment's result of western blotting of the experimental group, where the expression level of $p$ ERK had increased. This means that cells undergo increased proliferation and migration because of the effect of calcium hydroxide.

The final step of dentin regeneration is mineralization. In this study, alizarin red staining was used to find out the effect of calcium hydroxide on the mineralization of DPSCs and PDLSCs. More of the small round alizarin red-positive nodules were found in the cells grown in the culture with calcium hydroxide, and this tendency was more evident even in the naked eye when the mineralization induction media was used, than the normal growth media (Fig. 4). To analyze such data, quantitatively, the sample was destained and the absorbance was measured at $565 \mathrm{~nm}$. As a result, it was evident that calcium accumulation had comparatively increased in the cells grown in the mineralization induction media containing calcium hydroxide, than the other groups. Also, in comparing the DPSCs and PDLSCs, the mineralization effect was greater in the DPSCs (Figs. 4 and 5). We previously experimented wound healing assay for cell proliferation and the result was that DPSCs showed critically increased growth rates than the PDLSCs did. We concluded that the higher proliferation rate of DPSCs may lead to the calcium hydroxide-dependent mineralization effect of DPSCs.

To summarize the results, it was biochemically and physiologically evident that calcium hydroxide increased the recruitment, migration, proliferation, and mineralization of the DPSCs and PDLSCs. Such a result is valuable for the in vitro examination of the relationship between the DPSCs, recently focused as the source of cells that are important in the regeneration of dentin upon injury, and calcium hydroxide, the most commonly used pulp capping agent until now. Taking a step further in dentin regeneration, the effect of calcium hydroxide on the DPSCs is not only expected to simply activate it, as aforementioned, but also to show additional effects when autologous DPSCs, extracted from an impacted third molar or stem cells from human exfoliated deciduous teeth, are applied to the defective areas. ${ }^{37}$

Future studies must focus on the molecular and cellular changes playing an important role in tooth regeneration, physiology/embryology, the treatment-related procedures, and stem cell-related therapies, which will contribute to a better dental practice. ${ }^{38}$

We are now facing a new era of restorative dentistry, regulating the biological activity of the dental tissue to stimulate the wound healing process and tissue regeneration. A lot of the nature and potency of dental stem/progenitor cells remains elusive for further study, and the opportunity for such a study is extensive in dental tissue regeneration. Continuous study will definitely lead to proving more beneficial aspects in managing dental disease.

\section{Acknowledgment}

This work was supported by grants from the National Research Foundation of Korea (NRF) grant funded by the Korean government (MEST) (No. 2009-0066366) to Pill-Hoon
Choung and by the Ministry of Health and Welfare, the Republic of Korea, through the Musculoskeletal Bioorgans Center Program (no. 0405-BO01-0204-0006).

\section{Disclosure Statement}

The authors indicate no potential conflicts of interests.

\section{References}

1. Tziafas, D., Smith, A.J., and Lesot, H. Designing new treatment strategies in vital pulp therapy. J Dent 28, 77, 2000.

2. Schroder, U. Effects of calcium hydroxide-containing pulpcapping agents on pulp cell migration, proliferation, and differentiation. J Dent Res 64, 541, 1985.

3. Rutherford, R.B., Wahle, J., Tucker, M., Rueger, D., and Charette, M. Induction of reparative dentine formation in monkeys by recombinant human osteogenic protein-1. Arch Oral Biol 38, 571, 1993.

4. Rutherford, R.B., Spangberg, L., Tucker, M., Rueger, D., and Charette, M. The time-course of the induction of reparative dentine formation in monkeys by recombinant human osteogenic protein-1. Arch Oral Biol 39, 833, 1994.

5. Goldberg, M., Six, N., Decup, F., Buch, D., Soheili Majd, E., Lasfargues, J.J., Salih, E., and Stanislawski, L. Application of bioactive molecules in pulp-capping situations. Adv Dent Res 15, 91, 2001.

6. Gronthos, S., Mankani, M., Brahim, J., Robey, P.G., and Shi, S. Postnatal human dental pulp stem cells (DPSCs) in vitro and in vivo. Proc Natl Acad Sci U S A 97, 13625, 2000.

7. Miura, M., Chen, X.D., Allen, M.R., Bi, Y., Gronthos, S., Seo, B.M., Lakhani, S., Flavell, R.A., Feng, X.H., Robey, P.G., Young, M., and Shi, S. A crucial role of caspase-3 in osteogenic differentiation of bone marrow stromal stem cells. J Clin Invest 114, 1704, 2004.

8. Ohazama, A., Modino, S.A., Miletich, I., and Sharpe, P.T. Stem-cell-based tissue engineering of murine teeth. I Dent Res 83, 518, 2004.

9. Duailibi, M.T., Duailibi, S.E., Young, C.S., Bartlett, J.D., Vacanti, J.P., and Yelick, P.C. Bioengineered teeth from cultured rat tooth bud cells. J Dent Res 83, 523, 2004.

10. Shi, S., Bartold, P.M., Miura, M., Seo, B.M., Robey, P.G., and Gronthos, S. The efficacy of mesenchymal stem cells to regenerate and repair dental structures. Orthod Craniofac Res 8, 191, 2005.

11. Martin, P. Wound healing-aiming for perfect skin regeneration. Science 276, 75, 1997.

12. Tedder, T.F., Steeber, D.A., Chen, A., and Engel, P. The selectins: vascular adhesion molecules. FASEB J 9, 866, 1995.

13. Mathieu, S., El-Battari, A., Dejou, J., and About, I. Role of injured endothelial cells in the recruitment of human pulp cells. Arch Oral Biol 50, 109, 2005.

14. Jeon, S.H., Yoon, J.Y., Park, Y.N., Jeong, W.J., Kim, S., Jho, E.H., Surh, Y.J., and Choi, K.Y. Axin inhibits extracellular signal-regulated kinase pathway by Ras degradation via $\beta$ catenin. J Biol Chem 282, 14482, 2007.

15. Decup, F., Six, N., Palmier, B., Buch, D., Lasfargues, J.J., Salih, E., and Goldberg, M. Bone sialoprotein-induced reparative dentinogenesis in the pulp of rat's molar. Clin Oral Investig 4, 110, 2000.

16. Seo, B.M., Miura, M., Gronthos, S., Bartold, P.M., Batouli, S., Brahim, J., Young, M., Robey, P.G., Wang, C.Y., and Shi, S. Investigation of multipotent postnatal stem cells from human periodontal ligament. Lancet 364, 49, 2004. 
17. Troppmair, J., Bruder, J.T., Munoz, H., Lloyd, P.A., Kyriakis, J., Banerjee, P., Avruch, J., and Rapp, U.R. Mitogen-activated protein kinase extracellular signal-regulated protein kinase activation by oncogenes, serum, and 12-O-tetradecanoylphorbol-13-acetate requires Raf and is necessary for transformation. J Biol Chem 269, 7035, 1994.

18. Lewis, T.S., Shapiro, P.S., and Ahn, N.G. Signal transduction through MAP kinase cascades. Adv Cancer Res 74, 139, 1998.

19. Leonardi, E., Girlando, S., Serio, G., Mauri, F.A., Perrone, G., Scampini, S., Dalla Palma, P., and Barbareschi, M. PCNA and Ki67 expression in breast carcinoma: correlations with clinical and biological variables. J Clin Pathol 45, 419, 1992.

20. Holland, R., Souza, V., Nery, M.J., Faraco Júnior, I.M., Bernabé, P.F., Otoboni Filho, J.A., and Dezan Júnior, E. Reaction of rat connective tissue to implanted dentin tubes filled with mineral trioxide aggregate or calcium hydroxide. J Endod 25, 166, 1999.

21. Estrela, C., Pimenta, F.C., Ito, I.Y., and Bammann, L.L. Antimicrobial evaluation of calcium hydroxide in infected dentinal tubules. J Endod 25, 418, 1999.

22. Weissman, I.L. Stem cells: units of development, units of regeneration, and units in evolution. Cell 100, 157, 2000.

23. Blau, H.M., Brazelton, T.R., and Weimann, J.M. The evolving concept of a stem cell: entity or function? Cell 105, 829, 2001.

24. Fuchs, E., and Segre, J.A. Stem cells: a new lease on life. Cell 100, 143, 2000.

25. Harada, H., Kettunen, P., Jung, H.S., Mustonen, T., Wang, Y.A., and Thesleff, I. Localization of putative stem cells in dental epithelium and their association with Notch and FGF signaling. J Cell Biol 147, 105, 1999.

26. Yamamura, T. Differentiation of pulpal cells and inductive influences of various matrices with reference to pulpal wound healing. J Dent Res 64, 530, 1985.

27. Smith, A.J., Cassidy, N., Perry, H., Bègue-Kirn, C., Ruch, J.V., and Lesot, H. Reactionary dentinogenesis. Int J Dev Biol 39, 273, 1995.

28. Smith, A.J., Tobias, R.S., Plant, C.G., Browne, R.M., Lesot, H., and Ruch, J.V. In vivo morphogenetic activity of dentine matrix proteins. J Biol Buccale 18, 123, 1990.

29. Ruch, J.V. Odontoblast commitment and differentiation. Biochem Cell Biol 76, 923, 1998.

30. Gronthos, S., Brahim, J., Li, W., Fisher, L.W., Cherman, N., Boyde, A., DenBesten, P., Robey, P.G., and Shi, S. Stem cell properties of human dental pulp stem cells. J Dent Res 81, 531, 2002.

31. Shi, S., and Gronthos, S. Perivascular niche of postnatal mesenchymal stem cells in human bone marrow and dental pulp. J Bone Miner Res 18, 696, 2003.

32. Roberts-Clark, D.J., and Smith, A.J. Angiogenic growth factors in human dentine matrix. Arch Oral Biol 45, 1013, 2000.

33. Murray, P.E., Kitasako, Y., Tagami, J., Windsor, L.J., and Smith, A.J. Hierarchy of variables correlated to odontoblastlike cell numbers following pulp capping. J Dent 30, 297, 2002.

34. Murray, P.E., Matthews, J.B., Sloan, A.J., and Smith, A.J. Analysis of incisor pulp cell populations in Wistar rats of different ages. Arch Oral Biol 47, 709, 2002.

35. Murray, P.E., Stanley, H.R., Matthews, J.B., Sloan, A.J., and Smith, A.J. Age-related odontometric changes of human teeth. Oral Surg Oral Med Oral Pathol Oral Radiol Endod 93, 474, 2002.

36. Tziafas, D. The future role of a molecular approach to pulpdentinal regeneration. Caries Res 38, 314, 2004.

37. Miura, M., Gronthos, S., Zhao, M., Lu, B., Fisher, L.W., Robey, P.G., and Shi, S. SHED: stem cells from human exfoliated deciduous teeth. Proc Natl Acad Sci U S A 100, 5807, 2003.

38. Casagrande, L., Mattuella, L.G., de Araujo, F.B., and Eduardo, J. Stem cells in dental practice: perspectives in conservative pulp therapies. J Clin Pediatr Dent 31, 25, 2006.

Address correspondence to: Pill-Hoon Choung, D.D.S., Ph.D. Department of Oral and Maxillofacial Surgery

Dental Research Institute School of Dentistry Seoul National University 28 Yongon-dong Chongno-gu Seoul 110-749

South Korea

E-mail: choungph@snu.ac.kr

Received: January 23, 2009

Accepted: January 7, 2010

Online Publication Date: February 10, 2010 
